\title{
JOSEFA ACEVEDO DE GÓMEZ: DEL DESEO DE ESCRITURA A LOS PROCESOS DE LEGITIMACIÓN DE LA ESCRITORA EN COLOMBIA DURANTE EL SIGLO XIX ${ }^{1}$
}

\author{
Ana María Agudelo Ochoa \\ Universidad de Antioquia \\ ana.agudelo@gmail.com \\ "Los hombres miran como su patrimonio el templo de Minerva y si \\ entráis en él, os castigarán cruelmente esta usurpación. Os quieren \\ ilustradas, pero no literatas". \\ Josefa Acevedo de Gómez
}

\section{RESUMEN / ABSTRACT}

En este ensayo se revisan dos aspectos de la carrera escrituraria de la colombiana Josefa Acevedo de Gómez (1803-1861). En primer lugar, el deseo de escritura presente desde su niñez y que entra en conflicto con el modelo de mujer republicana, al cual está socialmente sometida. En segundo lugar, se abordan las estrategias de legitimación de la obra de la autora, las cuales se fundamentan en su injerencia en asuntos de carácter político. Finalmente se demuestra de qué manera la escritora juega con las disposiciones de la época concernientes al género femenino y logra inmiscuirse en el ámbito público a través de su pluma.

1 Este artículo se deriva de los proyectos de investigación Devenir escritora. Nacimiento y formación de las narradoras colombianas en el siglo XIX (1840-1870) y Formas históricas del intelectual colombiano. Una reconstrucción a partir de la prensa literaria (1850-1900), este último ejecutado con recursos de la Convocatoria de proyectos de investigación de Ciencias Sociales, Humanidades y Artes 2012, financiada por el Comité para el Desarrollo de la Investigación (CODI) de la Universidad de Antioquia; se inscribe en el marco de la Estrategia de sostenibilidad para grupos de investigación CODI 2013-2014. 
Palabras clave: Josefa Acevedo de Gómez; literatura colombiana del siglo XIX; literatura escrita por mujeres.

ABSTRACT: This paper studies two aspects of the writing of the Colombian author Josefa Acevedo de Gómez (1803-1861). The first aspect is the desire to write appeared in Acevedo's childhood and her conflicts with the model of Republican Women, which is socially subjugated. The second aspect is the strategy of legitimizing her literary work, which are based on its interference in political issues. Finally this text shows how Acevedo de Gómez uses strategically the conditions of her time, concerning the female, and she appears on the political scene.

KEY WORDS: Josefa Acevedo de Gómez; Colombian Literature of the 19th century; women's writing.

\section{EL DESEO DE ESCRITURA}

Josefa Acevedo de Gómez nace el 23 de enero de 1803 y su vida discurre a la par del movimiento independentista y el consiguiente surgimiento del Estado-nación colombiano, en un contexto caracterizado por la inestabilidad administrativa, los problemas económicos derivados del proceso de emancipación y la imperiosa necesidad de construir una identidad nacional. Como bien señala Guerra (2003), un rasgo común entre las recién conformadas naciones hispanoamericanas es precisamente que no son fruto de movimientos nacionalistas previos a los procesos independentistas y como consecuencia no se apoyan en una identidad colectiva -entendida como construcción cultural que implica una identidad política y una identidad cultural (186-187)-. La autora crece en el seno de una respetada familia de pensamiento liberal, que goza de buena posición en la sociedad colonial, sobresaliente en el ámbito intelectual, participante activa de la vida política y protagonista del movimiento de emancipación; poseedora, además, de un capital económico importante.

El padre de la escritora, José Acevedo y Gómez, descendiente de familia criolla ilustre, cursa estudios en el Colegio el Rosario -notable centro educativo fundado en 1653, donde se formó buena parte de la clase letrada de la Colombia decimonónica- y pertenece a un grupo de intelectuales inspirados por la Revolución francesa y la independencia de Estados Unidos. Se trata de un líder revolucionario reconocido por su elocuencia y capacidad de persuasión, quien hace fortuna por cuenta de su actividad comercial, ocupa cargos en la esfera pública como Procurador General y Regidor Perpetuo del Cabildo de Santafé, en 1808. Conocido como Tribuno del pueblo por su capacidad 
para encender con su excelente oratoria los ánimos del pueblo, llega a ser tildado por el virrey Antonio Amar y Borbón como "un criollo peligroso para el gobierno español” (Martínez, Josefa Acevedo, Ocampo). Es dueño de una impresionante biblioteca y lector de los clásicos griegos y latinos y de autores españoles. De sus habilidades con la pluma queda constancia en algunas misivas y relaciones que hace respecto de los acontecimientos que llevaron a la Independencia².

Por su parte, la madre de Acevedo de Gómez, Catalina Tejada, es una mujer de cultura excepcional para la época, preocupada por dar una buena formación a sus hijos, quien al quedar viuda se da a la tarea de inculcar en los pequeños "las ideas nobles, desinteresadas i liberales que animaron a su esposo" (Acevedo y Acevedo) ${ }^{3}$.

Desde pequeña, aflora en Acevedo el deseo de escritura: "Amaba la poesía y todas las ficciones de la imaginación, y á los doce años, sin saber escribir todavía, componía versos, casi todos lúgubres” (Acevedo de Gómez, Autobiografía 332), afirma en su nota autobiográfica escrita poco antes de morir ${ }^{4}$. Asimismo en su juventud, la autora es seducida por la lectura, actividad habitual para ella: "Leí novelas de amor en mi juventud, y creí en el ridículo amor de las novelas. Deseaba ser heroína; pero mi genio tímido, mis irresoluciones y mi mala figura me preservaron de aquella desgracia" (Autobiografía 332). En la misma nota autobiográfica referida antes, la autora narra un episodio de su adolescencia, que tal vez constituya el primer asomo de legitimación de su impulso escriturario:

2 Ver: "Historia del 20 de julio de 1810", carta dirigida a Carlos Montúfar; "Oficio acerca de la reunión del Cabildo de la Prov. de Tunja con motivo de los sucesos ocurridos en Samaná”; "Relación de lo que executó el M.I.C. justicia y regimiento de la M.N. y M.L. ciudad de Santafé de Bogotá, capital del Nuevo Reyno de Granada, para solemnizar el acto de la augusta proclamación que hizo dicha ciudad del Señor Don Fernando VII por Rey de España e Indias el día 11 de setiembre de 1808”. Documentos que reposan en la Biblioteca Luis Ángel Arango (Bogotá) y la Biblioteca Nacional (Bogotá).

En este artículo se mantiene la ortografía de las fuentes citadas.

$4 \quad$ Esta nota autobiográfica, escrita en 1861 por Acevedo de Gómez, cuando sentía cercana la muerte debido a una penosa enfermedad, fue publicada por primera vez en 1910 por su nieto Adolfo León Gómez, como parte de la obra El tribuno de 1810, que recoge documentos acerca de José Acevedo y Gómez, padre de la escritora. La nota aparece publicada por segunda vez acompañada del breve estudio "Autobiografismo post mórtem en Josefa Acevedo de Gómez" (Agudelo). 
Yo busqué pues aplausos extraños. Tenía diez y seis años cuando hice la pintura lamentable de una emigración. Estaba contenta de mi obra, y se la mostré á un doctor que entraba á casa con alguna franqueza. La leyó y me dijo al devolvérmela: "Pepita, usted va á ser un asombro”. Esta frase me llenó de satisfacción y orgullo y me decidió por la literatura (Autobiografía 333).

Pero es en el contexto del periodo de las retaliaciones de la monarquía española contra los ideólogos de la revolución de 1810, durante el cual se da la muerte de su padre y de otros hombres conocidos por la joven, cuando se intensifica la vena artística de la joven escritora:

Entonces mi sensibilidad se avivó [...] Escribía sobre estos sucesos rasgos sentimentales y elegías profundamente tristes; llevaba una especie de diario de las tiranías de los expedicionarios, y las pintaba con todos sus horrores (Autobiografía 333).

Infortunadamente no se han conservado los escritos referidos por Acevedo de Gómez en estas líneas. Pese a ello, las mismas señalan una temática que atravesará su producción: la Independencia, evento gracias al cual es posible iniciar un proyecto de nación y que "marca el punto de partida para lograr el progreso i felicidad de estas ricas comarcas” (Acevedo de Gómez, Cuadros149). Catalina Tejada, madre de la entonces joven escritora, reprueba los textos escritos por su hija en medio del dolor que genera la desaparición del padre, lo cual mortifica a la joven. También en su nota autobiográfica, Acevedo de Gómez refiere la relación problemática con su madre; la autora no solo siente que la mujer reprueba su inclinación literaria, sino que no la quiere como a sus otros hijos:

Mi madre manifestaba que prefería a mis hermanos, y á pesar de su deseo de parecer imparcial, yo veía esta preferencia, que no me afligía, porque no era envidiosa, pero que me arraigaba más y más a mis inclinaciones solitarias y mi genio brusco (Autobiografía 333).

Acevedo de Gómez construye una imagen de su madre como mujer severa, encargada de su educación moral y “mujeril”. Pero nunca expresa su amor hacia ella como lo hace hacia su padre. Incluso en la nota autobiográfica la figura de la madre se diluye, no se relata su muerte ni lo que la misma significó para la escritora. Por el contrario, la muerte del padre constituye una gran pérdida y se asocia a la exacerbación emocional que acompaña la inspiración. 
Cabe anotar en este punto que en el diario de la escritora cubano-española Gertrudis Gómez de Avellaneda (1814-1873), contemporánea de Acevedo de Gómez, se perciben elementos similares: profundo amor y admiración por el padre, cierta tensión con la madre, afición por la lectura desde la niñez y un carácter que la diferenció del común de las niñas. Respecto de la lectura, las impresiones de Gómez de Avellaneda son cercanas a las de la colombiana, en ambas la ficción desata los propios sentimientos románticos:

Más tarde, la lectura de novelas, poesías y comedias, llegó a ser nuestra pasión dominante. Mamá nos reñía algunas veces porque, siendo ya grandecitas, descuidáramos tanto nuestros adornos, y huyéramos de la sociedad como salvajes. Porque nuestro mayor placer era estar encerradas en el cuarto de los libros, leyendo nuestras novelas favoritas y llorando las desgracias de aquellos héroes imaginarios, a quienes tanto queríamos (Gómez de Avellaneda, en línea).

La figura del padre no representa conflictos para Gómez de Avellaneda. Como señala Catelli:

La figura del padre no ofrece conflictos intrínsecos[...] El padre es presentado como alguien íntegramente semejante a aquello que se parece, a su exterioridad y, por si fuera poco, sus virtudes están dadas desde siempre [...] Era noble, intrépido, veraz, generoso e incorruptible en su hogar (352-355).

Algo similar ocurre en el caso de Acevedo de Gómez. El padre es un modelo, una figura a seguir, un valeroso patriota y ciudadano modelo: es inspirador. Tanto que la autora escribe su biografía. El hombre era muy cariñoso con su hija, le permite experimentar con la pluma, pero se burla de las tempranas composiciones de la autora, así lo refiere ella misma:

Mi padre elogiaba mis poesías porque me amaba con predilección; pero después se burlaba de ellas en mi presencia, lo que necesariamente producía mal efecto. Mi hermano mayor, joven de juicio, grandes talentos y poeta él mismo, las parodiaba haciendo entrar en ellas algunos rasgos de mi persona. Esto me humillaba, me causaba mal humor y hacía más bruscos mis modales (Autobiografía 332).

La madre, por su parte, no aprobaba tales inclinaciones literarias, como se ha señalado, pues había formado a su hija en el marco de las convenciones de la época. De ella recibía, según la misma autora: 
Muchas lecciones de moral, buenos ejemplos, la educación mujeril necesaria para gobernar una casa con economía, aseo y orden, las más tocantes advertencias é instrucciones sobre nuestra santa Religión, y mil preceptos, consejos y amonestaciones que frecuentemente he olvidado en la hora precisa de ponerlos en práctica (Autobiografía 331-332).

Durante la niñez y adolescencia, la escritura es avivada en Acevedo de Gómez por las ensoñaciones sentimentales, los infortunios familiares por motivos políticos y patrióticos y la tristeza que produce la autoconsciencia de la propia fealdad. La autora se describe así:

Fui pequeña de cuerpo y mal proporcionada; ojos sin expresión; frente blanca y espaciosa; boca desairada; pelo castaño y lacio; tez blanca y rosada; brazos cortos y bien hechos; cuello blanco y de graciosa forma; manos y pies pequeños pero feos; dientes blancos, grandes, desiguales y de mala calidad, pues a los treinta y tres años ya se habían caído todos; talle corto y grueso, y en fin, un todo que sin ser muy fea, no llama la atención de nadie ni podría procurar á mis oídos las dulzuras de la galantería. Mis modales en la juventud fueron agrestes (porque era sentimental sin ser bella, y esto me hacía huraña y tímida) (Autobiografía 333-334).

La descripción es interesante porque revela que el carácter sentimental se asocia a las mujeres bellas, mientras que los mismos rasgos de carácter en una mujer poco agraciada denotan tosquedad. El aspecto físico al parecer determina la relación de la joven con los hombres de su edad; en consecuencia el aspecto sentimental causa decepciones:

Yo deseaba ser amada y me figuraba que un joven á quien veía por anteojo era muy querido; pero si el mudaba de vestido, ya yo no lo conocía, lo que prueba que mi imaginación, extraviada por la lectura de novelas, era la que me hacía anhelar por sentimientos prematuros [...] Sufrí pesares fantásticos y escribí versos desesperados que por fortuna nadie vio (Autobiografía 333-334).

Tal entrecruzamiento de la literatura con sus propias vivencias sentimentales, tan desafortunadas, radican en la concepción acerca de la novela que tiene Acevedo de Gómez, como género dañino, causante de las ensoñaciones que le causan tanto pesar. Postura generalizada en la época y que desata constantes 
advertencias por parte de estamentos como la Iglesia, que asegura que la lectura de novelas corrompe las débiles mentes de las mujeres.

Pese a los infortunios sentimentales de juventud, en 1822 Acevedo de Gómez contrae matrimonio con Diego Fernando Gómez, primo de su padre, con quien tiene dos hijas, Amalia y Rosa; además, reconoce como propio un hijo de Gómez que al momento contaba con cinco años de edad. El esposo es abogado notable, formado en el Colegio del Rosario, quien además de participar en la gesta independentista, ocupa importantes cargos entre los que se cuentan Diputado al Congreso de las Provincias Unidas en 1816, Gobernador de El Socorro en 1819, Senador en 1824 y Magistrado de la Corte Suprema de Justicia en 1827. Este hombre se interesa por la formación intelectual de su esposa, a quien instruye en gramática, geografía, aritmética, historia, francés, asimismo guía su lectura mediante "obras serias y escogidas" (Caicedo 327). Acerca de la relación con su esposo, la autora señala: "Su superioridad me imponía, y él hacía de ella un noble uso, tratando de instruirme y de hacer de mí una compañera inteligente y juiciosa” (Acevedo de Gómez, Autobiografía 334). La relación con su esposo distaba de los ideales novelescos que muy seguramente inundaban la mente de la autora, quien no estaba enamorada de Gómez cuando contrajo nupcias con él:

En aquella sazón un primo hermano de mi padre, hombre de talento, conocido mérito y grandes esperanzas me propuso casamiento. Aunque diez ocho años mayor que yo y padre de un chiquillo que debía vivir con nosotros, yo acepté. Ni él ni yo teníamos amor. El me estimaba y deseaba establecerse; yo agradecí su franqueza, correspondía su estimulación y quería ser jefe de familia (Autobiografía 334).

Aunque es indiscutible que las relaciones intelectuales con el padre y con el esposo marcarían a Acevedo de Gómez, es importante señalar que tales vínculos constituyen al mismo tiempo una estrategia de control patriarcal a través de la iniciación, que se solapa tras la figura del tutor masculino. No obstante, la escritora logra llevar adelante su proyecto creador aun después de la temprana muerte del padre y de la separación de su esposo. Es precisamente cuando asume una vida solitaria, sin pareja y sin un padre o esposo proveedores, que se concentra en su carrera. Así, logra superar a ambas figuras masculinas en el ámbito de las letras.

Además de las anotaciones respecto de la escritura dispersas a lo largo de su nota autobiográfica, Acevedo de Gómez lanza comentarios sobre su 
relación con las letras en algunas de sus otras obras. En Tratado de economía doméstica se refiere a los motivos que la impulsan a escribir:

Debo advertir que no es el deseo de adquirir reputación literaria el que me ha puesto la pluma en la mano. Una voluntad decidida por comunicar a las damas lo que me parece útil, i la necesidad de aumentar en lo posible los medios de subsistencia, son las causas únicas que me han determinado a escribir (Tratado, p. i).

Tal declaración de principios marca el camino que se impone como escritora, no solo en la vía de una responsabilidad con un público específico, sino la consciencia de un oficio; puesto que la autora encuentra en la escritura una posibilidad económica. En la "Introducción i dedicatoria" que abre Cuadros de la vida privada de algunos granadinos para instrucción i divertimento de los curiosos (1861)indica que desea escribir para hacer oposición a un periódico satírico que circula en el momento (Cuadros viii). En el mismo texto refiere un diálogo que sostiene con su hermano, donde le expresa su preocupación de que la obra no sea leída y por lo mismo pierda los costos de la impresión, de lo cual se deduce que le preocupa el aspecto económico: "Me detiene una cosa, contesté, i es, que si escribo en este sentido casi nadie me leerá $[\ldots$... i perderia los costos de la impresion de mi obra, lo cual, como soy pobre, no es poco para mí” (Cuadros viii).

A pesar de la falta de formación literaria, de los miembros de su familia es Josefa la pluma más prolífica y la única que se adentra en el campo de la ficción. A los veinte años ya había compuesto varios poemas, entre ellos "Una tumba en los Andaquíes", en el cual hace referencia a las condiciones del final de la vida de su padre, quien huyendo de las represalias del gobierno

\footnotetext{
Hubo un tiempo muy grato á mi memoria/ Cuando á mi tierno padre acompañaba,/ Y que él con sus caricias me llenaba/ De gratitud, de complacencia y gloria.// Mas pasó cual la rápida centella/ Que surca el aire con brillante vuelo;/ Su alma feliz habita el alto cielo,/Y del mundo se borra hasta su huella.// Su nombre y sus riquezas se acabaron./ ¡ Nada me resta de él sobre la tierra!/ ¡ Ni la urna funeral donde se encierra/ La ceniza de aquellos que finaron!// Esa arboleda enmarañada, espesa,/ Que crece en la montaña silenciosa,/ Cubre la tumba donde en paz reposa/ Cubierto de hojarascas y maleza.// Su cadáver, que un hijo desolado/ Cubrió de tierra, llanto y oraciones,/ Lejos de tumultuosas poblaciones/ No será por los hombres profanado.// Nunca sobre el sepulcro solitario/ El rastro se estampó de paso humano:/ Jamás del hombre codiciosa mano/ Sembró sobre este suelo funerario.// No hay monumento, ni inscripción, ni losa/ Do se eternice vanidad mundana,/ Pues que la omnipotencia soberana/ Cubrirlo quiso de una selva umbrosa.// Tan sólo se descubre en la enramada/ Una cruz de
} 
español en contra de los revolucionarios que encabezan los eventos del 20 de julio de 1810 debe pasar los últimos meses de su vida en la inhóspita región de los Andaquíes, donde muere y es enterrado. Esta temática marcaría una constante en la autora: el uso de las referencias biográficas, autobiográficas e históricas en su obra.

No hay información que permita afirmar que la autora haya asistido a tertulias, salones o cenáculos, lo cual daría cuenta de su participación en este tipo de espacios de sociabilidad literaria. Algunas de sus reflexiones acerca de los usos e imposiciones de la vida social de su época la muestran como una mujer reacia a participar de los "rituales" sociales propios de su sexo:

Yo he sido [...] incapaz de aprender las artes del agrado y los modales de la sociedad distinguida" (Autobiografía 335). "Le doy gracias á Dios porque me ha hecho conocer tántas personas estimables y virtuosas en la sociedad que he frecuentado, que no ha sido muy extensa ${ }^{6}$ (Fragmentos 339).

Acevedo de Gómez igualmente señala su aparente gusto por una vida retirada del centro urbano; de hecho la mayor parte de su vida la escritora vivió en las haciendas El Chocho y El Retiro: "Le doy gracias [a Dios] porque me ha concedido vivir largos años fuéra de las grandes poblaciones, especialmente de Bogotá” (Fragmentos 339). Algunos apartes de su discurso presentan a una mujer que opta por alejarse de las exigencias y usos de la sociedad capitalina y que opta por la austeridad. Aunque no todo es humildad: la escritora atribuye al aislamiento la posibilidad de dedicarse a la escritura:

He empleado en esto [la escritura] aquellos ratos perdidos que otras mujeres dan á la sociedad de que casi siempre he estado separada, ó los dedican al cultivo de las artes de agrado i de habilidades que yo nunca he poseído (Advertencia s.p.).

Esta autoconsciencia del lugar privilegiado de la mujer letrada es el refugio o defensa discursiva de muchas autoras del siglo XIX que utilizan diversos modos de la retórica de la humildad para afirmarse en el ámbito público. Incluso en las obras de la autora, sobre todo en las de carácter autobiográfico,

madera ya destruida,/ Y el ángel compañero de su vida/ Vela sobre su tumba abandonada./// (Una tumba s.p.).

Énfasis añadido. 
se descubre que Acevedo de Gómez sí participa activamente de la vida social y política de la época, y que los modos de intervención corren por cuenta de los espacios de sociabilidad cultural y política en la que está inmersa, y gracias a los cuales logra su legitimación como escritora.

Pese a la supuesta subordinación del impulso escriturario a las funciones asociadas a su género, Acevedo de Gómez logra desarrollar un proyecto creador y consigue la legitimación en su momento. El acervo de su obra publicada constituye prueba irrebatible de la solidez del primero. En 1844 aparece uno de sus primeros libros, un manual de formación titulado Ensayo sobre los deberes de los casados, obra que publica gracias al apoyo económico de su sobrina Dolores Neira ${ }^{7}$; en 1848 publica el segundo manual, Tratado sobre economía doméstica para el uso de las madres de familia; en 1854 aparecen Poesías de una granadina y la Biografía del doctor Diego Fernando Gómez; en 1857 publica Oráculo de las flores y de las frutas; en 1860, Recuerdos nacionales. José Acevedo y Gómez; en 1861 (año de su muerte) aparece Cuadros de la vida privada de algunos granadinos. También hacen parte de su obra publicada Las damas de Bogotá al general Moreno, con ocasión del restablecimiento del gobierno legítimo en mayo de $1831^{8}$ y la Biografía del teniente coronel Alfonso Acevedo Tejada.

En cuanto a la obra inédita, es asimismo copiosa. Adolfo León Gómez advierte sobre la existencia deDiario, la comedia La coqueta burlada, Catecismo republicano y Mis ideas (Josefa Acevedo 325), información repetida por críticos posteriores, y a la que se suma la supuesta existencia de otras asimismo inéditas: En busca de almas, Mal de novios; las biografías de Luis Vargas Tejada y Vicente Azuero (Rodríguez, Josefa Acevedoy Bibliografía; Martínez, Acevedo de Gómez). Varios críticos e historiadores de la literatura colombiana insisten en la existencia del diario del que habla León Gómez, texto que podría ofrecer datos acerca de la formación de la autora (Luque, Aristizábal, Martínez, Acevedo de Gómez y Rodríguez, Josefa Acevedo) -Rodríguez incluso llega a afirmar que la autora "se aleja del lente público y escribe impresiones personales de sus circunstancias como mujer de su época”

\footnotetext{
Como agradecimiento a este apoyo pecuniario, Acevedo de Gómez le dedica a su sobrina su siguiente ensayo de formación, Tratado sobre economía doméstica.

$8 \quad$ Es importante señalar en este punto que ni Josefa Acevedo en su nota autobiográfica (Autobiografía) ni su nieto Adolfo León Gómez (El tribuno de 1810) mencionan la publicación de dicho documento, el cual es referido por las investigadoras Jaramillo y otras (1991), Rodríguez (Bibliografía) y Martínez (María Josefa).
} 
(Josefa Acevedo115) - mas ninguno de tales estudiosos aporta información acerca de la ubicación del mismo. Luque y Caicedo también mencionan un folleto intitulado Mis ideas, aunque no ofrecen datos de ubicación. En la nota autobiográfica, la misma Acevedo de Gómez enumera sus obras:

He escrito un tratado sobre los deberes de los casados, que me parece bueno; cuatro biografías (fuera de esta), en que he procurado honrar con la verdad; un tratado de Economía doméstica, apenas pasable; algunas poesías buenas; muchas medianas y muchas más detestables, pero ninguna inmoral. He trabajado varios artículos de periódicos que no enumero, pero que juzgados obra de otros escritores, han sido aplaudidos por hombres de mérito, causándome eso tal placer, que casi he dejado el incognito para recoger mis laureles. Escribí Los quince días de Alberto en Madrid, para N. Gómez que hoy me parece que no me estima; un tratado sobre La Beneficencia, dedicado á mí querido hermano José; los Cuadros sobre la vida privada, dedicados al mismo; muchos romances y un drama que están aún inéditos y cuyo mérito debe ser poco. Tengo otros muchos manuscritos, como El Desagravio, El Panorama, una pieza dramática sobre un asunto quiteño, las Meditaciones sobre la Pasión y La Pola. Pero creo que todo irá al fuego (Autobiografía 335-336).

Toda esta información da cuenta de una obra copiosa que tuvo que exigir largos periodos de dedicación a las letras, lo cual implica una postura innovadora acerca de la relación de la mujer con la escritura. Cabe resaltar la extrema autoconsciencia crítica de este texto; Acevedo de Gómez no solo lista sus obras y reconoce su autoría, sino que evalúa su producción. Parece estar especialmente complacida con las biografías y algunas poesías, géneros a los que se circunscriben la mayor parte de sus obras editadas y en la línea de lo permitido a las mujeres que optan por la pluma. Caso contrario el de las obras de carácter narrativo, los romances y las piezas teatrales, que sucumben a los deseos de ocultamiento de la escritora.

\section{ESTRATEGIAS DE LEGITIMACIÓN}

En cada época, una serie de instituciones que detentan la autoridad determinan las formas culturalmente apropiadas de comportamiento masculino y femenino, es decir, sustentan un sistema de géneros normativizado que delimita las 
fronteras del actuar social (Conway et al. 169), sistema que afecta tanto el inconsciente cultural y el habitus de los artistas, como el orden simbólico ${ }^{9}$. De la mujer republicana se espera una total dedicación al hogar, a sus labores como madre y esposa. Cualquier incursión en el espacio público debe ser una derivación de tales funciones, de ahí que la enseñanza y la caridad sean actividades permitidas.

A pesar de este panorama, en la modernidad aparecen las grietas del modelo y la mujer decimonónica colombiana participa de la vida política y cultural; a través de la literatura le es posible adoptar públicamente las posiciones de lectora y escritora. El impulso de la prensa le abre espacios para desenvolverse en ambas actividades, de esta manera la escritura es un medio por el cual las mujeres aportan a la construcción de la nación: “The pen, not the sword, was her patriotic contribution. In this way she situated herself as the good republican mother, wife and sister, the shaper of cultural memory, the chronicler of the patriots' feats, and the means by which they were commemorated for posterity" 10 (Davies, p. x). No obstante, las temáticas y formas discursivas están controladas. La escritora ha de ocuparse de temas relacionados con la vida familiar, lo amoroso y lo íntimo, debe evitar temas masculinos, esto es, del orden público (Mataix 24).

En este contexto, resalta el caso de la escritora colombiana Josefa Acevedo de Gómez, quien constituye un caso de mujer que logra entrar en la dinámica de las luchas que se libran en el ámbito intelectual a través de la escritura; cuyos proyecto creador y aporte en materia de capital simbólico abonan el terreno a autoras posteriores. Pese a las restricciones para inmiscuirse en política que son impuestas a las mujeres republicanas, la configuración de

$9 \quad$ El habitus es definido por Bourdieu como: "Estructura estructurante, que organiza las prácticas y la percepción de las prácticas [...] es también estructura estructurada: el principio del mundo social es a su vez producto de la incorporación de la división de clases sociales. [...] Sistema de esquemas generadores de prácticas que expresa de forma sistémica la necesidad y las libertades inherentes a la condición de clase y la diferencia constitutiva de la posición, el habitus aprehende las diferencias de condición, que retiene bajo la forma de diferencias entre unas prácticas enclasadas y enclasantes (como productos del habitus), según unos principios de diferenciación que, al ser a su vez producto de estas diferencias, son objetivamente atribuidos a éstas y tienden por consiguiente a percibirlas como naturales (170-171).

10 "La pluma, no la espada, fue su contribución patriótica. En este sentido ella se sitúa a sí misma como la buena madre, esposa y hermana republicana, la modeladora de la memoria cultural, la cronista de las hazañas patrióticas, y el medio por cual éstos fueron conmemorados en la posteridad”. Traducción de la autora. 
Acevedo de Gómez precisamente como sujeto político es determinante en la configuración de su posición autorial. La pugna entre el modelo de mujer republicana y el deseo de escritura -estrategia que conduce a la figuración política- quedan ilustrados por la misma Acevedo de Gómez cuando describe, en uno de sus textos, la jerarquía de sus funciones, donde la vida familiar está aparentemente por encima de las inclinaciones literarias, discurso comprensible en el marco de las exigencias sociales en materia de género:

El cuidado de la propiedad de mi esposo, la crianza y educación de mis hijas, la formación de ese verjel que hoy produce tan ricos frutos, la vigilancia sobre toda la familia y la beneficencia con los pobres ocuparon casi todos mis días. Por la noche leía y escribía algo de las obritas que he publicado después (Acevedo de Gómez, Autobiografía 334-335).

Los temas y problemas abordados en sus obras, la publicación de las mismas en periódicos y libros prueban que participa de la lucha por un lugar en el naciente campo literario colombiano. Visto desde la perspectiva de los temas que le interesan, es de subrayar que si bien aborda los motivos del matrimonio, el rol social de la mujer y la religiosidad, también se atreve con temas transgresores y que dan cuenta de que es consciente de la problemática social de la época: el cuestionamiento que hace al marcado sistema de clases sociales, cuando trata el problema de las clases menos favorecidas; su crítica al sistema de reclutamiento, un asunto de varones; su interés por temas políticos, como defensora de la causa independentista con una postura crítica clara acerca del sistema colonial; su abordaje de asuntos históricos, como el caso de la vida de su padre, y su interés por mostrar otras razas en sus obras. Podría aducirse que el sentimiento de caridad religiosa y el amor a su familia subyacen al interés por tales temas, tal vez así sea, pero es innegable que hay una postura crítica frente a las problemáticas sociales del momento que ella trata de solucionar por la vía del proyecto civilizador, apegándose en ciertos aspectos al modelo conservador.

El periodo de mayor publicación y recepción de Acevedo de Gómez coincide con buena parte de la denominada "hegemonía liberal”, que se extiende de 1849 a 1880, con su modelo defensor de la separación de poderes y el voto popular, entre cuyos objetivos se cuenta el desmonte del Estado colonial, la libertad de expresión y pensamiento, la igualdad de todos los hombres ante la ley y la limitación del poder de la Iglesia. El ambiente liberal en la esfera del poder sumado a iniciativas del periodismo genera un espacio 
estimulante para el ejercicio de la lectura y el cultivo de la escritura por parte de las mujeres. Aunque también se vive en medio de un clima de disputa entre partidos políticos y una clase popular trabajadora que pugna por hacer realidad la promesa de igualdad que se defendía en el discurso emancipador.

Trabajos recientes en el ámbito hispanoamericano se detienen en el fenómeno de formación y legitimación de las escritoras del siglo XIX; Graciela Batticoure, por ejemplo, se concentra en los casos de Mariquita Sánchez, Eduarda Mansilla y Juana Manuela Gorriti. Batticuore demuestra cómo la red de relaciones en los ámbitos político y cultural son determinantes en los procesos de legitimación de estas tres autoras. En el caso concreto de Colombia, Josefa de Gómez (1803-1861) juega un papel fundamental tanto en las dinámicas de sociabilidad de su época, entendida en el marco del "deseo de civilización", como precursora de la profesionalización del oficio de escritora en el país, circunstancia a la cual contribuye definitivamente su posición en los entramados social y político de buena parte del siglo XIX colombiano.

Documentos y obras de Josefa Acevedo de Gómez confirman que mantiene contacto permanente con personalidades de la vida política de su época. Notables personajes de la esfera pública neogranadina frecuentaban el hogar de los Gómez Tejada, de ahí que la autora tuviera la oportunidad de cultivar amistad con escritores y políticos de la época, entre quienes se cuentan Rufino Cuervo ${ }^{11}$, Luis Vargas Tejada ${ }^{12}$, Juan Francisco Arganil “y otras personas instruidas que [...] sirvieron de favorable estímulo a su genio y ayudaron a formar en ella el gusto por el cultivo de las letras en los días de su juventud" (Caicedo 326-327). En su testamento agradece a los amigos que la acompañaron a lo largo de su vida, menciona un listado de más de veinte personas a quienes pide "honren mi memoria pronunciando una palabra

11 (1801-1853). Político y periodista, vicepresidente de de la Nueva Granada de 1845 a 1849. Padre del filólogo Rufino José Cuervo.

12 (1802-¿1829?). Escritor, político y dramaturgo, considerado el padre del teatro cómico colombiano. A pesar de su pobre procedencia, logra una excelente formación: domina varias lenguas, cultiva diversos géneros literarios, asimismo el periodismo. Participa en la conspiración septembrina, atentado en contra de Simón Bolívar efectuado por un grupo de opositores a las políticas dictatoriales del libertador. Como consecuencia, Vargas es perseguido y debe huir. Muere muy joven, a los 27 años, al parecer tratando de cruzar un río en el Orinoco con el fin de desplazarse a Venezuela. 
de favor en caso de que la maledicencia me persiga después de la muerte” (Fragmentos 340). Las personalidades nombradas por la escritora son:

\begin{abstract}
Anselmo Pineda, ${ }^{13}$ Januario Triana, ${ }^{14}$ F. de P. López, respetable doctor M. Tobar [...] los doctores Alfonso, Cárdenas, Martínez, Blagborne, Quintero, Motta y M. Samper, ${ }^{15}[\ldots]$ los señores Belver, Uribe, Maldonado, Liévanos [...] mis amigas Paris, Bernal, Calcaño, Hincapié, Merizalde, Acosta, Malos, Contreras, Cadenas, Benítez, Manrique, I. Ricaurte, Alfonso, etc. etc. (Fragmentos 340).
\end{abstract}

La incursión de Acevedo de Gómez en política va más allá de las visitas de algunas personalidades al hogar paterno y al propio, como mujer casada años más tarde; de hecho, mantiene correspondencia con José Hilario López ${ }^{16}$, Tomás Cipriano de Mosquera ${ }^{17}$, José de Obaldía, Anselmo Pineda y Rufino Cuervo, importantes figuras políticas (León Gómez, El tribuno, Luque, Rodríguez, Josefa Acevedo ${ }^{18}$. Igualmente interesante es la relación de la escritora con los principales implicados en la conspiración septembrina ${ }^{19}$. Entre los personajes cercanos a la autora que participan del atentado se cuentan Luis Vargas Tejada, Vicente Azuero y Francisco Arganil. De los dos primeros la autora escribe sus

13 (s.d.). Militar antioqueño cercano a José María Córdova. Ejerció como gobernador de Panamá (1843).

14 (s.d.). Político y escritor. Ejerció como gobernador de la provincia de Tequendama (1854-1855).

15 (1825-1899). Político y economista. Colaborador de una importante cantidad de periódicos decimonónicos. Su legado en el estudio de la economía nacional es de resaltar.

$16 \quad$ (1798-1869) Militar y político liberal. Ejerce la presidencia del país entre 1849 y 1853.

(1798-1878). Político y militar de ideología liberal, ejerce la presidencia los periodos 1845 a 1849, 1861 a 1864 y de 1866 a 1867. Emite una serie de decretos que restringen el poder de la Iglesia en el país.

18 Algunas cartas que prueban que la autora mantiene correspondencia con algunos de estos personajes han sido reproducidas en El tribuno de 1810, de Adolfo León Gómez (1910).

19 Atentado que se realiza en contra de Simón Bolívar el 25 de septiembre de 1828, por un grupo de liberales inspirados en la Revolución francesa, como fruto del descontento con la proclamación del libertador como jefe supremo del Estado. El grupo de opositores entra a la fuerza en el Palacio Presidencial la noche del 25 de septiembre con el fin de ajusticiar a Bolívar, quien escapa por una ventana y logra salvarse. 
biografías $^{20}$. En cuanto a la interesante relación de Acevedo de Gómez con Arganil, hay que señalar que este hombre, al parecer de nacionalidad francesa, trató de vincularse a la actividad política del país, si bien fue menospreciado por Bolívar y Santander. Jacobino declarado, instruye a la autora en asuntos relativos a la Revolución francesa, en la cual estuvo implicado (Caicedo) ${ }^{21}$. Según la historiadora Aída Martínez Carreño, Acevedo de Gómez escribe "Retrato de J. F. Arganil” en 1839, mas no ofrece información acerca de la localización del texto (María Josefa 46). Adolfo León Gómez se refiere a la relación entre ambos personajes:

La señora Acevedo fue una de las pocas personas que supieron á fondo los secretos del misterioso personaje histórico que con el nombre del doctor Francisco J. Arganil figuró en este país después de haber desempeñado importante papel en la revolución de Francia, su patria, como se supo más tarde. Bastante tiempo vivió el doctor Arganil en la hacienda El Chocho, del doctor Diego Fernando Gómez, y allí cultivó estrecha amistad con él y con la señora Acevedo á quien confió todos sus papeles; y era tal el cuidado de ella en conservarlos reservados, que los llevaba consigo hasta en los viajes más cortos; $y$ al acercarse su muerte, no queriendo que por su culpa se descubriesen los graves secretos confiados á su lealtad, hizo quemar aquellos papeles en su presencia (El tribuno 326).

La escritora comparte la ideología del liberalismo de primera mitad de siglo, aquel fundamentado en los postulados de la Revolución Francesa, heredero

20

(1787-1844). Político y escritor neogranadino, ideólogo del liberalismo, partido del cual es considerado precursor. Ocupa diversos cargos políticos a lo largo de su vida. Cercano a Francisco de Paula Santander, se declara en contra de las políticas autoritarias de Simón Bolívar. Una narración realizada por Josefa Acevedo de Gómez acerca de las vicisitudes que enfrenta Azuero una vez exiliado como consecuencia de su participación en la conspiración septembrina se encuentra incluida en Antología política (1981). El relato de Acevedo de Gómez, fragmento de una misiva sin dato de fecha ni destinatario, muestra la facilidad de la autora para la prosa, asimismo el sentimiento que la hermana con Azuero: “A tal punto de prescindencia de las cosas públicas, no obstante su fervoroso, ardiente y nunca desmentido patriotismo, a veces imprudente, lo redujeron las multiplicadas, odiosas y encarnizadas persecuciones que se le hicieron” (Acevedo de Gómez, Narración 383).

21 Del curioso carácter de la relación entre ambos y del interés de la escritora por temas científicos da cuenta una anécdota bastante particular: en 1851 la autora pide el cráneo de Juan Francisco Arganil, muerto en 1841, para estudiarlo con el mapa frenológico de Gall (Eljaiek en línea). 
de la Ilustración, sustento del ideario que guía el movimiento revolucionario, el cual a su vez está fundado sobre el concepto de igualdad. Al respecto señala Rocío Serrano, en su interesante ensayo "Los principios liberales en la obra de Josefa Acevedo de Gómez”, que a través de sus textos, la escritora promulga activamente principios liberales, pese a que en la época recae sobre las mujeres la prohibición de participar en política (135). Entre las ideas que defiende se cuentan:

El hogar doméstico como empresa, educación de la familia por la esposa, construcción del refugio doméstico, eliminación del fanatismo religioso, rechazo a la milicia y a la pena de muerte, solidaridad y caridad cristiana (137).

No obstante, como ya se ha dicho, discrepa del liberalismo que se consolida como partido político en 1848 -cuando se funda el Partido Liberal Colombiano-, aquel que defiende a ultranza las libertades individuales, que separa los poderes de Estado de los de la Iglesia, expulsa a los jesuitas, adopta el régimen federal e introduce el matrimonio civil y el divorcio. Paradójicamente, a la fundación del partido político antecede la Sociedad Filológica, de la que formaron parte los principales vinculados a la conspiración septembrina. Varios de estos hombres fueron familiares y amigos de la autora: Luis Vargas Tejada y Francisco Arganil. En tal contexto navega Acevedo de Gómez, liberal y amiga de un jacobino que tiene a la vez un profundo sentimiento religioso y critica las tendencias liberales de mediados del siglo. De la extrema consciencia política de la autora, da testimonio esta cita:

No sé si habré sido buena ó mala ciudadana, porque he amado y profesado los principios liberales. Las leyes reformadoras de esta última época no me han gustado todas; y entre las que me desagradaron, unas fue por la forma y otras por la substancia. Las que me parecieron buenas son en mi concepto deficientes, y esto tal vez consiste en que es más fácil criticar que legislar... (Autobiografía 337).

Ahora bien, pese a la solidez de su proyecto creador y a injerencia en política, Acevedo de Gómez se muestra retóricamente indecisa en cuanto al reconocimiento de la autoría de sus obras, temor que la impulsa en algunos casos a esconderse tras el seudónimo - Una granadina, Una señora granadina o a sus iniciales J. A. de G.- y también tras el anonimato. Tales formas de protección de la identidad son muy comunes en Occidente durante el siglo XIX, pues las mujeres temen exponer su nombre en público, dudan de la 
calidad de su obra o se amilanan ante la crítica. Según relata la autora en su nota autobiográfica, solía publicar artículos en prensa sin mencionar su autoría, los cuales "han sido aplaudidos por hombres de mérito, causándome esto tal placer, que casi he dejado el incógnito para recoger mis laureles" (Acevedo de Gómez, Autobiografía 335). En varios casos, se le pide autorización para estampar su nombre en alguna edición de una de sus obras, que hasta el momento ha aparecido anónima. Este fenómeno señala que la autora utiliza la exhortación de los notables para reconocer su identidad como escritora. Prueba de ello es la invitación que le extiende el vicepresidente José de Obaldía para que admita como propio nada menos que un texto de carácter político:

La lectura de esa útil composición nos ha cautivado al Presidente de la República y á mí [...] los liberales todos encontrarán en ella mucho que aplaudir [...] ojalá que su bondad me autorice para poner al frente de su cuaderno, ó el nombre de la señora, ó bien sus iniciales, ó en último caso, este seudónimo: Una Granadina (Obaldía 342-343).

Claramente, Acevedo de Gómez participa en política, tiene la capacidad de discutir con altos mandos del gobierno y es reconocida como interlocutora por los mismos. Igualmente interesante, y señal del reconocimiento del que goza la escritora, es la carta firmada por F. E. de Ingunza ${ }^{22}$, en la cual le expresa su admiración por uno de los manuales de comportamiento, le comenta que realizó una reimpresión de la misma y se disculpa por no haber reconocido su autoría:

Mas en París, después de terminada ya la reimpresión, se me informó haciéndoseme saber era usted la autora, que tánto buscaba, su calidad y posición social. Cuánto siento, señora, que noticia de tánto interés hubiese llegado á mí tan tarde, privándome del gusto de ocuparme, particularmente en su dedicatoria, de circunstancias de tanto valer que enaltecen y deben llenar de satisfacción y orgullo á la antigua Colombia! (Ingunza 345).

La misiva de Ingunza, además de ilustrar el tópico del reconocimiento de la autoría femenina, revela que las obras de la autora circulan en el extranjero,

22 Por las iniciales de quien firma la misiva y el contexto de la misma, se deduce que se trata de Francisco Esteban de Ingunza y Basualdo, político y viajero peruano, autor de Viajes por el Oriente (1852). 
y que también allí las mismas son aplaudidas. Por otro lado, en esta carta sale a relucir el asunto de los derechos de autor; se ve como una falla que el libro fuera reimpreso sin contar con la autorización de la escritora y sin que se le reconocieran, probablemente, las utilidades derivadas de su venta.

\section{ALGUNAS CONCLUSIONES}

Josefa Acevedo de Gómez es la iniciadora de un proceso de profesionalización de la mujer escritora en Colombia, logra intervenir con sus prácticas culturales en el espacio público durante un periodo en que se gestan el campo intelectual y literario colombiano. Es justo reconocer que antecede a Soledad Acosta de Samper y que con ella se inicia la incursión en la exploración a partir de la escritura de asuntos públicos por parte de una mujer.

Los logros de Acevedo de Gómez en el campo de las letras se explican en gran medida porque se mueve en los límites impuestos por el sistema de géneros vigente, y además utiliza ambiciosamente sus redes familiares y sociales para lograr el reconocimiento. Su ajuste a los modelos político y religioso dominantes le permite figurar públicamente en una época en que es restringido a las mujeres (Davies et al.). Es consciente del lugar que debe ocupar en ese momento y su insistencia en que no pretende glorias literarias no se deriva de la modestia sino de su conocimiento del terreno en que se mueve, de que las glorias literarias son asunto exclusivo de los hombres:

Los hombres miran como su patrimonio el templo de Minerva y si entráis en él, os castigarán cruelmente esta usurpación. Os quieren ilustradas, pero no literatas. (Acevedo de Gómez Ensayo 65)

Pese a la consciencia de tal situación, la escritora osa recorrer los caminos de las bellas letras y expresar su postura, algunas veces solapadamente, otras de manera explícita, acerca de la situación de las mujeres y de su posibilidad de acceder a la escritura. Un poema publicado en El Mosaico en 1860 prueba que ya en su madurez se torna más temeraria y no se amedrenta ante la necesidad de expresar su postura acerca de ciertos escenarios que deben enfrentar las mujeres. La obra en cuestión se intitula "El cabrón lejislador”:

Preguntaban cierto día/A un cabron sus compañeras/¿Porqué él libertad tenia/I eran ellas prisioneras/¿Porqué él doquiera buscaba/ Los pastos a su elección/I a ellas solo les pasaba/Una medida racion?/ 
Las leyes, dijo el maldito,/Os marcan vuestro deber,/Violarlas es un delito/I es preciso obedecer./Replicó entonces su esposa:/¿̇I porqué las quebrantais/I en tan importante cosa/Tan mal ejemplo nos dais?/ Tus reflexiones me ofenden,/El grave cabron le dice:/Las leyes no me comprenden/Porque yo mismo las hice;/I aunque la justicia tuerza/ Ya de este o del otro modo,/Mis barbazas i mi fuerza/Me autorizan para todo./Por último, no te asombres/(Concluyó el sabio profundo)/ Que esto mismo hacen los hombres/Legisladores del mundo.// (El cabrón s.p.).

Mediante el juego satírico que acude a la figura del aquelarre, la autora da la voz a las mujeres y les permite cuestionar la autoridad masculina. Podría señalarse este poema como la obra más contundente de Acevedo de Gómez en ese sentido, por recurrir a la sátira y al juego con una situación transgresora y por la terminología empleada para referirse al político.

Acevedo de Gómez juega con las reglas impuestas a la mujer por la sociedad de su tiempo. En sus ensayos de conducta femenina se presenta como una defensora de aquella ideología que repliega a la mujer a sus funciones domésticas, no obstante es precisamente en tales obras donde disemina afirmaciones que contraviene el orden establecido (como es el caso del epígrafe que abre este artículo). En su nota autobiográfica, escrita al final de su vida, se representa como una mujer que lleva a cabo su tarea en solitario, sin descuidar las labores hogareñas, consciente de los límites impuestos socialmente, pero constante en la escritura y persistente en la publicación, a pesar de ocultar su nombre al principio de su carrera. La autorrepresentación de Acevedo de Gómez se sostiene en la tensión entre el modelo del ángel del hogar y de la mujer pública. Al dibujarse como una adecuada administradora del hogar que pone por encima de sus propias necesidades las de su esposo, sus hijos y los más necesitados cumple con los preceptos de la época. Pero a renglón seguido, en el mismo texto, se reconoce como una imperfecta administradora del hogar, quien se separa de su esposo, con un deseo de escribir constante y con la necesidad de ser reconocida como autora.

El orden, la economía, la hospitalidad, el trabajo, la misericordia y la justicia se practicaban hasta donde yo podía en nuestra casa, conforme á las lecciones de mi padre, mi madre y mi esposo. Ni es esto decir que no hubiera algunos nublados, algunas fallas ligeras, algunos pesares y alternativas (Autobiografía 334). 
La lucha contra el anonimato, que resulta paradójica ante su insistencia en el seudónimo y en el anonimato, aparece al final de su vida. En el mismo texto autobiográfico se ocupa de manera narcisista de dejar claro cuáles son sus obras con el fin de "impedir que se me atribuyan otras ó se me nieguen éstas" (Autobiografía 336); tal sumario, citado páginas atrás, más los motivos tras su redacción, indican que hacia el final de su vida, Acevedo de Gómez se sabe escritora y quiere dejar claro para la posteridad cuáles son sus textos, si bien una importante cantidad de los mismos no fueron publicados.

Coincidimos con Susana Zanetti cuando afirma que como mujer republicana de pensamiento liberal, defensora del catolicismo y comprometida con el proyecto de nación, esta autora posee, a pesar de las adversidades, una gran capacidad de trabajo y vocación literaria que le permiten plantar la semilla de la profesionalización del oficio de escritora en el país (Zanetti 172). En su caso, su producción en el ámbito de la narrativa de ficción además de aportar al proyecto de consolidación nacional -tras el cual se esconde un “deseo de civilización”- contribuye a la conformación de un imaginario nacional decimonónico, de ahí que su obra sea bien recibida en el momento. El afán de construir una tradición literaria nacional y hacerse de un corpus de textos propios es característico del emergente sistema cultural colombiano decimonónico, el cual buscaba consolidarse y de esta manera sentar las bases de una emancipación mental respecto del sistema colonizador, esto es, el español.

\section{BIBLIOGRAFÍA}

Acevedo de Gómez, Josefa. Tratado sobre economia domestica para el uso de las madres de familia i de las amas de casa. Bogotá: José A. Cualla. 1848. Recuperado de: http://www. banrepcultural.org/blaavirtual/economia/tratado-sobre-economia-domestica-para-el-usode-las-madres-de-familia-y-de-las-amas-de-casa

“Una tumba en los Andaquíes”. Poesías de una granadina. Bogotá: Torres Amaya, [1823] 1854. s.p.

“Advertencia”. Poesías de una granadina. Bogotá: Torres Amaya, 1854. s.p.

Ensayo sobre los deberes de los casados ( $5^{\mathrm{a}}$ ed). Bogotá: Imprenta de Francisco Torres Amaya. 1857. Recuperado de: http://www.bibliotecanacional.gov.co/recursos_user/ digitalizados/fvergara_6_pza2.pdf

“Fragmentos del testamento de la señora Acevedo de Gómez”. En: Adolfo León Gómez. El tribuno de 1810. Biblioteca de Historia Nacional. Vol. VII. Bogotá: Imprenta Nacional. [1860] 1910. 337-341. 
“El cabrón legislador”. El Mosaico, Año II, trim. 4 (51). 1860, diciembre 29. s.p. “Autobiografía de doña Josefa Acevedo de Gómez”. En: Adolfo León Gómez. El tribuno de 1810. Biblioteca de Historia Nacional. Vol. VII. Bogotá: Imprenta Nacional. [1861] 1910. 331-337.

Cuadros de la vida privada de algunos granadinos, escritos para instrucción y divertimento de los curiosos. Bogotá: Imprenta de El Mosaico, 1861.

“Narración de Josefa Acevedo de Gómez”. En: Francisco de Paula Santander y Vicente Azuero. Antología política. Bogotá: Instituto Colombiano de Cultura. [s.d.] 1981. 383-386.

Acevedo de Gómez, Josefa y Alfonso Acevedo Tejada. "Biografía del General José León Gómez, Adolfo”. El tribuno de 1810. Biblioteca de Historia Nacional. Vol. VII. Bogotá: Imprenta Nacional. [1850] 1910.

Agudelo Ochoa, Ana María. “Autobiografismo post mórtem en Josefa Acevedo de Gómez”, Lingüística y Literatura 58, julio-diciembre. 2010. Disponible en: http://aprendeenlinea. udea.edu.co/revistas/index.php/lyl/issue/view/868/showToc

Aristizábal, Patricia. Escritoras colombianas del siglo XIX. Cali: Universidad del Valle, 2007.

Batticuore, Graciela. La mujer romántica. Lectoras, autoras y escritores en la Argentina: 1830-1870. Buenos Aires: Edhasa, 2005.

Bourdieu, Pierre. La distinción. Madrid: Taurus, 1988.

Caicedo Rojas, José. “Josefa Acevedo de Gómez”. Apuntes de ranchería. Medellín: Bedout. [1871] 1973. 323-333

Catelli, Nora. En la era de la intimidad. Rosario: Beatriz Viterbo, 2007.

Conway, Jill K. y otras. "El concepto de género”. ¿Qué son los estudios de mujeres? (167178). México: FCE., 1998.

Davies, Catherine. "Introduction". En: Sarah Sanchez (trad.), Catherine Davies (intr.). A Treatise on Domestic Economy, for the Use of Mothers and Housewives by Josefa Acevedo de Gómez. Nottingham: Critical, Cultural and Communications Press, 2007. I-XXVIII.

Davies, Catherine et al. "Gender, Patriotism and Social Capital: Josefa Acevedo de Gómez and Mercedes Marín”. En: Catherine Davies y otras. South American Independence: Gender, Politics, Text. Liverpool: Liverpool University Press, 2006. 183-209.

Eljaiek Rodríguez, Gabriel Andrés. "Sobre cómo sacarle pelos a una calavera”. La Habana Elegante, segunda época 40, 2007, invierno. Recuperado de: http://www.habanaelegante. com/Winter2007/Expresion.html

Gómez de Avellaneda, Gertrudis. Autobiografía. Diario de amor: obra inédita. Edición digital basada en la de Madrid, M. Aguilar [1839] [1901]. Recuperado de: http://www. cervantesvirtual.com/obra/diario-de-amor-obra-inedita--0/

Guerra, François-Xavier. "Las mutaciones de la identidad en la América hispánica”. En: Antonio Annino y François-Xavier Guerra (coords). Inventando la nación. Iberoamérica. Siglo XIX. México: FCE., 2003. 185-220.

Ingunza, F. E. de. "Carta dirigida a Josefa Acevedo de Gómez, Washington, 19 de junio de 1853”. En: Adolfo León Gómez. El tribuno de 1810. Biblioteca de Historia Nacional. Vol. VII. Bogotá: Imprenta Nacional. [1853] 1910. 345. 
León Gómez, Adolfo. El tribuno de 1810. Biblioteca de Historia Nacional. Vol. VII. Bogotá: Imprenta Nacional, 1910a.

“Josefa Acevedo de Gómez”. En: Adolfo León Gómez. El tribuno de 1810. Biblioteca de Historia Nacional. Vol. VII. Bogotá: Imprenta Nacional, 1910b. 323-327.

Luque Valderrama, Lucía. La novela femenina en Colombia. Bogotá: Universidad Javeriana, 1954.

Martínez Carreño, Aída. “Acevedo de Gómez, Josefa”. Biblioteca Luis Ángel Arango Virtual, 2004. Recuperado de: http://www.lablaa.org/blaavirtual/biografias/acevgome.htm

“Josefa Acevedo de Gómez: su vida, su obra”. En: Ana Cecilia Ojeda A., Rocío Serrano Gómez y Aída Martínez Carreño. Josefa Acevedo de Gómez. Bucaramanga: Universidad Industrial de Santander. Dirección Cultural, 2009a. 9-32. Recuperado de: http://cultural.uis.edu.co/files/JOSEFA_ACEVEDO.pdf

“María Josefa Acevedo de Gómez. Cronología”. En: Ana Cecilia Ojeda A., Rocío Serrano Gómez y Aída Martínez Carreño. Josefa Acevedo de Gómez. Bucaramanga: Universidad Industrial de Santander. Dirección Cultural. 2009b, 33-53. Recuperado de: http://cultural.uis.edu.co/files/JOSEFA_ACEVEDO.pdf

Mataix, Remedios. "La escritura (casi) invisible. Narradoras hispanoamericanas del siglo XIX”. Anales de Literatura Española 16, Narradoras hispanoamericanas desde la Independencia a nuestros días, serie monográfica 6, 2006. Recuperado de: http://rua. ua.es/dspace/bitstream/10045/7269/1/ALE_16_02.pdf

Obaldía, José de. “Carta dirigida a Josefa Acevedo de Gómez, Bogotá, 12 de abril de 1852”. En: Adolfo León Gómez. El tribuno de 1810. Biblioteca de Historia Nacional. Vol. VII. Bogotá: Imprenta Nacional [1852] 1910. 342-343.

Ocampo López, Javier. “Acevedo Gómez, José. Biografía”. Biblioteca Virtual del Banco de la República, 2004. Recuperado de: http://www.lablaa.org/blaavirtual/biografias/acevjose.htm

Osuna Patiño, Néstor. Constituciones iberoamericanas. Colombia. México: Universidad Nacional Autónoma de México, 2006. Recuperado de: http://www.bibliojuridica.org/ libros/libro.htm?l=2212

Rodríguez Arenas, Flor María. “Josefa Acevedo de Gómez: modelos iniciales de la escritura femenina en el siglo XIX en Colombia”. El soldado y Angelina. ¿Y las mujeres? Medellín: Universidad de Antioquia [1861] 1991. 109- 132.

Bibliografía de la literatura colombiana del siglo XIX. Buenos Aires: StockCero, 2006.

Serrano, Rocío. “Los principios liberales en la obra de Josefa Acevedo de Gómez”. En: Ana Cecilia Ojeda A., Rocío Serrano Gómez y Aída Martínez Carreño. Josefa Acevedo de Gómez. Bucaramanga: Universidad Industrial de Santander. Dirección Cultural, 2009. 133-157. Recuperado de: http://cultural.uis.edu.co/files/JOSEFA_ACEVEDO.pdf

Zanetti, Susana. La dorada garra de la escritura. Buenos Aires: Beatriz Viterbo, 2002. 